\title{
Understanding fat preference and consumption: applications of behavioural sciences to a nutritional problem
}

\author{
BY DAVID J. MELA \\ Consumer Sciences Department, Institute of Food Research, Reading RG6 6BZ
}

Because of the associations between fat intakes and the development of several major chronic diseases, governmental and health authorities in Western nations have voiced consistent recommendations for reductions in fat consumption over the past 35 years (Cannon, 1992). In these countries, fat consumption has been arguably the foremost public health nutrition issue over most of this period; yet, in contrast to the massive accumulation of human and animal studies related to the potential physiological and pathological effects of fat consumption, the nutrition literature contains a paucity of work on the possible bases for this behaviour.

The populations of North America and western Europe, with economic and market access to a diet of virtually any possible composition, consume $37-42 \%$ of their food energy as fat. It is unclear why in a free-choice situation they choose to consume fat at this level and, correspondingly, why compliance with recommendations to reduce fat intakes has been so poor. Such issues of food selection and eating behaviour fall within the domain of both nutrition and more traditional behavioural sciences, and they are best addressed by individuals and groups with expertise in both.

The present paper briefly considers factors which may contribute to understanding the basis for fat consumption, with examples of how ideas and methods derived from the behavioural sciences can contribute to research and understanding of a major nutrition issue. In order to limit the discussion, the emphasis is on contributions from experimental and social psychology, and only limited reference will be made to the animal literature.

\section{WHY DO WE EAT FAT? PSYCHOBIOLOGICAL CONSIDERATIONS}

Understanding human fat consumption at the most fundamental level requires an analysis of the psychobiological forces which might serve to promote and then reinforce and maintain this behaviour. More specifically, how might a desire to ingest foods with fat-associated sensory characteristics develop? The possible bases for preferences for fats and fat-containing foods have been addressed in previous reviews (Mela, 1990, 1992; Birch, 1992; Reed et al. 1992) as have the more general and theoretical issues relating to the acquisition of sensory and food preferences by children and adults (e.g. Rozin \& Fallon, 1981; Rozin, 1989; Shepherd, 1989; Rozin \& Schulkin, 1990; Ray \& Klesges, 1993; Mela \& Catt, 1995).

\section{A genetic predisposition?}

While there is no evidence for a genetically endowed 'fat preference', experiments suggest that animals may express ostensibly unlearned preferences for fat-associated 
texture and flavour preferences at birth or soon thereafter (Ackroff et al. 1990; Elizilde \& Sclafani, 1990; Ackerman et al. 1992). However, there is good evidence that positive hedonic responses to flavours can result from prenatal exposure to volatile flavours (from the maternal diet) in utero (Schaal \& Orgeur, 1992). In addition, some flavour or texture preferences may be acquired through experience with the characteristics of maternal milk (Mela \& Catt, 1995). In both cases, these involve learning mechanisms analogous to those described later. A further challenge to the idea that fat-associated flavour preferences might be inborn is that there are hundreds or thousands of these aromas, which are typically both highly complex and characteristic of specific foods. These lines of evidence suggest that specific genetically-transmitted preferences for fat-associated flavours are unlikely to explain their sensory appeal, but some learned aspects of sensory preferences could appear 'innate', as the learning may take place before or shortly after birth.

Although a true genetic contribution to preferences for fat-associated sensory qualities cannot be entirely ruled out, evidence and obvious mechanisms for this are lacking. More general genetic differences in putative receptive elements and/or neurophysiological mediators could give rise to individual differences in preferences for fat-associated qualities, by influencing the development and expression of conditioned preferences (see p. 455) through effects on the reinforcing properties or sensation of fats. Differences in preferences of rats for fat-containing foods and solutions have been linked to a galaxy of hormonal and neurotransmitter systems, including but not limited to those involving enterostatin (Sörhede et al. 1993), adrenal hormones (Bligh et al. 1990), serotonin (Kanarak \& Dushkin, 1988), dopamine (Weatherford et al. 1990), neuropeptide Y (Welch et al. 1993) and galanin (Leibowitz \& Kim, 1992). Drewnowski (1992) has suggested that human preferences for sweet, high-fat foods may be mediated by endogenous opiate release. However, it is not clear that this or other systems are in some way specific to fat-containing stimuli, or perhaps have more general roles as mediators in the development and maintenance of liking for preferred foods.

\section{Does the preference reflect physiological need?}

With few exceptions (e.g. salt preferences in Na deficiency), the general phenomenon of such 'gustatory wisdom' lacks strong experimental support (Galef, 1991). Dietary fats are a source of three essential dietary components: (1) essential fatty acids, (2) fat-soluble vitamins, (3) energy for storage or oxidation. The only nutritional requirements which must be fulfilled by lipids are those established for essential fatty acids and fat-soluble vitamins, and these can be satisfied readily by diets extremely low in total fat content. Human diets in which fat comprises $10 \%$ or less of energy are not uncommon, and the low fat content per se does not appear to pose any specific nutritional risk to otherwise healthy adults. Furthermore, common evidence indicates that many widely consumed and popular high-fat foods are not notable sources of such specific nutrient classes. In a review of animal and human literature, Reed et al. (1992) conclude that a true specific appetite for fat is unlikely to be an important determinant of fat acceptance and consumption. However, the energy content or other physiological or psychological effects of fats may positively contribute to a learned preference for their sensory characteristics. 


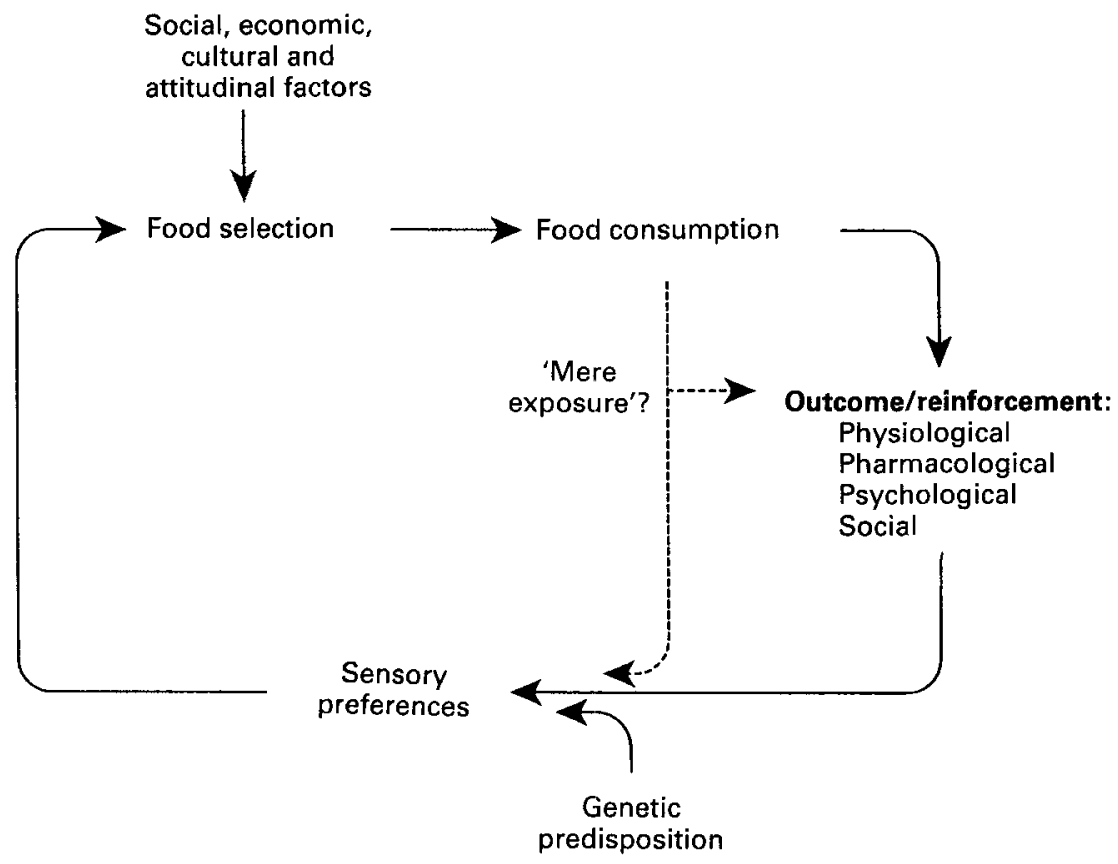

Fig. 1. Schematic representation of factors influencing acquisition of sensory preferences.

\section{Is the preference learned?}

There is a strong case for a predominant role of learning processes in the formation of most sensory preferences. Numerous experiments have shown that human subjects and other animals are endowed with the ability to recognize and learn from the contexts and consequences associated with ingestion of specific foods or sensory qualities (see Booth, 1985; Rozin \& Schulkin, 1990; Sclafani, 1990), and many examples of human likes and dislikes for specific foods can be best explained by such processes. This type of learning may also underlie 'mere exposure' effects, whereby repeated experience with a sensory quality leads to enhanced liking. A general schematic version of these processes is depicted in Fig. 1.

Liking for specific sensory qualities can be acquired or enhanced by their temporal linkage with positive physiological, psychological, pharmacological, or even social outcomes. For example, it seems reasonable to ascribe preferences for (innately disliked) items such as coffee and alcoholic beverages to their psychobiological effects (e.g. Rogers \& Richardson, 1993). Perhaps less obviously, the apparent human preference for the sensory properties of fats in foods is probably best explained by this type of learning. The available evidence suggests that the development of preferences for the sensory characteristics of fat sources is attributable to their association with the post-ingestive effects of fats (Johnson et al. 1991; Kern et al. 1993; Lloyd et al. 1994; Lloyd \& Rogers, 1994; for reviews, see Mela, 1990, 1992). 
Flavour preferences in human subjects have been shown to be influenced by the energy content (as fat or carbohydrate) of conditioning media (Booth et al. 1982; Birch et al. 1990; Johnson et al. 1991; Kern et al. 1993). The recent studies of Birch and colleagues (Johnson et al. 1991; Kern et al. 1993) with children are particularly clear evidence that these processes are operative in human subjects. In these studies, manipulation of fat content in novel-flavoured yoghurts effected shifts in flavour preferences; specifically, with repeated consumption there was a relative increase in preference for the flavours which had been associated with a higher fat content. The procedures make a strong case for attributing the outcome to the metabolism or other reinforcing effects of fats. Such studies convincingly demonstrate that sensory acceptance can be readily shifted by association with differential nutritional properties of foods. Energy density appears to be an important factor, and experiments in both animals and human subjects suggest that the expression of conditioned preferences for nutritive fats is enhanced by food deprivation (Ackroff et al. 1990; Kern et al. 1993), although it is possible that food deprivation per se may shift sensory preferences (Sclafani \& Ackroff, 1993). These phenomena may have implications for long-term acceptance of, for example, reduced-fat products, which disengage the traditional linkage of specific sensory properties with particular psychobiological or metabolic effects of foods.

It is also possible that the development of preferences for fats may relate to effects not directly associated with energy metabolism. Little is known about the possible influence of the psychobiological effects of foods (e.g. on mood and performance), and the role of situational and environmental variables as mediators of conditioned sensory preferences. Recent advances in testing of mood and cognitive performance may allow such effects to be identified. Many idiosyncratic differences and shifts in likes and dislikes could presumably be accounted for by associations with these psychobiological properties of foods or their interaction with the eating environment (Rogers \& Richardson, 1993; Rogers \& Lloyd, 1994). Recent studies by Lloyd et al. (1994) and Lloyd \& Rogers (1994) point to links between the fat:carbohydrate value of a meal and subsequent mood and cognitive performance, leading these authors to suggest that these effects could serve in the acquisition and maintenance of preferences for particular levels of fat.

Although these fundamental influences are undoubtedly operative in human subjects, further work is needed to identify their role relative to other factors contributing to expressed sensory preferences, and their possible links to food selection and intake.

\section{SENSORY ACCEPTANCE AND CONSUMPTION OF FATS}

Interest in individual sensory perceptions and acceptance of fat-containing stimuli largely began with the work of Drewnowski and colleagues (Drewnowski \& Greenwood, 1983; Drewnowski et al. 1985) in the mid-1980s. They reported that obese and recently reduced, formerly obese, individuals show enhanced preferences for higher fat levels in a sweetened-milk-based test system, and suggested that liking and consumption of sweet, high-fat foods might play a causal role in obesity (Drewnowski et al. 1985). Mela \& Sacchetti (1991) subsequently reported a significant positive correlation of sensory preferences for fats in a battery of sweet and savoury foods with percentage body fat in subjects of normal weight-for-height. However, they found no association between sensory responses and fat consumption from $7 \mathrm{~d}$ diet records.

Human gauging of fat content appears to be predominated by textural cues (Mela \& 
Marshall, 1992), and recent work has focused on characterization of the stimulus properties that give rise to the sensation of the presence of fat (e.g. Mela et al. 1994a,b). However, a role for olfaction cannot be completely ruled out. Ramirez (1992) has demonstrated that rats may utilize olfaction, e.g. the odour of fat decomposition products, to identify the presence of different fats and discriminate amongst them. In human subjects, weight status is not apparently associated with differences in the perception of intensity of fat content (i.e. fattiness or creaminess) of stimuli (Mela et al. $1994 a, b)$. Other research suggests that elderly subjects may have reduced sensitivity to fats (Schiffman et al. 1992); however, we have not observed consistent differences between older and younger subjects (Mela et al. 1994a,b).

Although casual observation makes a strong case for a significant role of sensory preferences in diet selection, few studies have actually found clear associations between sensory and food or nutrient intake measures (Shepherd \& Farleigh, 1989). Consistent links between fat intakes and sensory hedonic judgements have not been found in studies focusing on fats (Pangborn \& Giovanni, 1984; Pangborn et al. 1985; Mela \& Sacchetti, 1991). This is not necessarily surprising, as such studies generally have not taken account of the food-related attitudes and beliefs held by consumers, nor the social and economic factors which influence eating patterns. Furthermore, blind sensory testing does not provide consumers with information that is used in making normal food selections or in forming sensory-affective judgements (Aaron et al. 1994). Finally, diets of similar nutrient composition may differ substantially in the sensory quality of their fatcontaining foods and, with increasing numbers of foods containing fat- and sugarreplacement technologies, nutrient composition is becoming increasingly disassociated from sensory properties. Therefore, we might expect sensory factors to be more important than nutrient intakes in determining brand or food-type selection. However, consumer trials indicate that perceived changes in taste quality of foods still may be a major factor in acceptance of dietary change (Lloyd et al. 1995).

More recent studies have examined the potential adaptation of sensory preferences to long-term changes in diet. There is good evidence that the most preferred level of salt in foods can be reduced by consumption of a low-Na diet, and may increase when foods are chronically supplemented with salt (e.g. Bertino et al. 1982, 1986; Blais et al. 1986). This appears to be a psychological phenomenon related to sensory exposure, and not a physiological effect of modified Na intake per se (Beauchamp \& Engelman, 1991). This would seem to offer hope that dietary modifications initially having poor acceptance may, over time, become more palatable. Animal studies suggest that preferences for fats may be influenced by the fat content of the preceding diet (Tepper \& Friedman, 1989; Reed \& Friedman, 1990; Warwick et al. 1990), but in studies with human subjects there is rather less documented evidence. The most commonly cited example is the case of individuals shifting from consumption of full-fat to low-fat or skimmed milk, which is apparently associated with increasing acceptance of the latter and dislike for the former. This finding has extensive anecdotal support but has been the focus of limited scientific evaluation. The general applicability of this specific case is also difficult to interpret because consumers are familiar with and reliably recognize and differentiate full-fat and skimmed milk, and will hold established attitudes toward and beliefs about these products (Tuorila, 1987; Shepherd, 1988).

Mattes (1993) has recently presented results which suggest that long-term exposure to diets reduced in fat is associated with reductions in the preferred levels of fat in foods in 
blind tests, but only amongst subjects who do not use reduced-fat or fat-substituted products as discretionary fat sources. These findings would seem to indicate that reductions in the preferred levels of fat in foods are, like salt, dependent on reduced sensory exposure, not overall intake. We (Mela et al. 1993) found that extended home use did not have any unique facilitating effect on liking for specific reduced-fat foods (potato crisps and cheese); however, subjects were blind to product identities during both home use and sensory testing. The results suggest that, in the absence of specific cognitive cues or an overall change in the sensory or nutritional composition of the diet, consumers do not exhibit any spontaneous change in liking for the sensory characteristics of reduced-fat versions of foods. This is suggested also by the results of Laitinen et al. (1991), who reported that diabetic subjects reported liking fatty foods less after 3 months of diet therapy, but showed no change in sensory scores for cheeses or milks of medium and high fat contents. 'Mere exposure' may be sufficient to shift preferences (Mela \& Catt, 1995), but long-term sensory habituation (or failure to habituate) may in part result from additional consumer knowledge (e.g. label information) and is perhaps an outcome of interactions with consumer attitudes, beliefs, and expectations. Such a role for cognition in sensory judgements of nutritionally-modified foods is clearly demonstrated by the results of Aaron et al. (1994), who found that presentation of nutritional information on fat content of spreads shifted sensory judgements in a direction more consistent with an individual's beliefs; i.e. hedonic responses from subjects with more positive attitudes toward reduced-fat or full-fat spreads were significantly greater in the respective label condition.

Clearly, fundamental psychobiological factors and expressed sensory preferences operate within a much larger framework of influences on food choice, eating behaviour, and nutrient intake. Study of the social and attitudinal factors which influence the selection and consumption of fat-containing foods requires investigators to find out more about the subjects, and to seek out and directly ask consumers what they are doing and why.

WHAT CAN SURVEYS TELL US? CONSUMER PERCEPTIONS AND PREDICTORS OF FAT INTAKE

Many nutritionists view studies based on surveys, interviews, and other self-reports with considerable suspicion, presumably because of their deceptively simple appearance, and apparent lack of hard, objective data. Rozin (1981) tells the allegorical story of a Martian scientific body which has decided to fund research to develop an understanding of the Earth game of American football and is now reviewing proposals from Martian academics. The review committee seriously considers proposals which use quantitative data, such as measurements based on the players' numbers, physiological recordings from the participants and spectators, body positioning and limb movements, and so on. One application suggests setting up animal models of the game. However, 'There was one proposal which was easy to reject. . . . The authors (from the fringe of science, at best) proposed to simply observe the general flow of the game, and to supplement and guide these observations with interviews of the players, in an attempt to find out what the game was all about. The committee unanimously agreed that this approach was not quantifiable, and that it relied on verbal reports, which were of questionable scientific status.' Clearly, properly designed questionnaires can play a critical role in assessing the 
motivations and beliefs of consumers, efficiently generating information with explanatory power not readily derived from other methods.

There is now a sizeable literature addressing the relevant attitudinal and belief characteristics of individuals, and relating these to their intended or actual consumption of high-fat foods (for reviews, see Stafleu et al. 1991-2; Shepherd, 1992; Tuorila, 1992) or overall fat intake (Stafleu et al. 1994). This type of work attempts to unravel the underlying social psychological forces which direct food selections and, ultimately, suggest where educational, communication, or intervention programmes might be most effectively directed. These studies have generally found knowledge to be poorly related to dietary behaviour or behavioural intent; in contrast, attitudinal measures have much more substantial predictive power. Overall, variation in personal attitudes toward the pleasantness or taste of foods, and to their perceived health implications, seem to hold particular relevance, while social pressure appears to be rather less important. Differences in relation to age, sex, and social class have been identified in some of these studies, and this information may suggest also where nutrition intervention efforts might be tailored to specific population subgroups. In addition, the methods developed in this area have been successfully applied to understand differences in sensory judgements (Aaron et al. 1993) and responses to point-of-purchase nutrition information (Aaron et al. 1995). Current research is increasingly directed toward understanding the basis of attitude formation and the effects of various strategies for attitude and behaviour change.

Recent survey data indicate that, overall, the majority of British consumers, across different social and demographic groups hold generally positive attitudes toward fat reduction and largely recognize and accept current consensus regarding the health aspects of fat intake (Tate \& Cade, 1990; Lloyd et al. 1993). Furthermore, they indicate that they would know how to achieve such a reduction, and show no strong consensus in self-reports of barriers to change (Lloyd et al. 1993). In agreement with these positive attitudes, a majority of consumers indicate that they have reduced their fat intakes, and report having made a number of healthy dietary changes (Sheiham et al. 1990; Lloyd et al. 1993). This would seem to be cause for optimism amongst public health nutritionists. At the very least, it says that educational measures intended to specifically increase awareness of the fat-disease link may be largely redundant.

However, these self-reported changes are clearly not supported by actual population intake data. For example, over $60 \%$ of UK consumers indicate that they have reduced their fat intake (Lloyd et al. 1993); yet, fat consumption has remained stable at approximately $40-41 \%$ of energy across all socio-economic classes for the past 25 years (Ministry of Agriculture, Fisheries and Food, 1993). The dichotomy between actual behaviour and consumer self-reports of their behaviour might suggest that such surveys are of little value. However, this is only true if reported behaviour changes are taken at face value, as a proxy for dietary intake data derived from more objective methods. An alternative view is that consumers may have honest misperceptions of the changes they have made, or of the effectiveness of those changes. This interpretation is supported by recent findings from our laboratory (Paisley, 1994), which show that (1) perceptions of relative fat intake are not significantly correlated with actual fat intake, (2) perceived level of past change is positively correlated with perceived current fat intake, negatively correlated with likelihood of making future changes, but not at all related to actual fat intakes. This may help to explain why consumers may hold very positive attitudes to fat 
reduction, yet indicate little intention of making relevant changes in dietary habits (Lloyd et al. 1993). Basically, many consumers seem to believe they already have made effective changes. This information has potentially important implications for effective public health nutrition guidance.

Other findings indicate that consumers may have substantial misconceptions regarding their personal fat intakes, and view their own personal intakes as unrealistically low (Greene et al. 1993; Lloyd et al. 1993). For example, Lloyd et al. (1993) found that equal numbers of consumers in the highest tertile of actual fat intake characterized their personal fat intake as low $v$. high. Other work from this laboratory supports the finding that British consumers tend to underestimate their likelihood of having a high fat consumption level relative to others they know (Paisley, 1994) or the average person of their sex and age (Sparks et al. 1995). Such beliefs may reflect the 'optimistic bias' which consumers commonly exhibit in judging their own personal risks of, for example, disease, accident, or illness (Weinstein, 1989). In the case of fat, it appears that consumers may have an inappropriate reference for the attributes of high-fat diets and the people who consume them, believing that such a diet must consist largely of so-called 'junk' foods, and believing that individuals with a high-fat diet must be overweight.

Misjudgements of personal fat intakes might also reflect knowledge deficits, particularly with regard to the fat content of common foods and their relative contribution to the overall diet. As noted previously, beliefs about degree of past change or current level of fat intake may bear little relationship to actual fat intakes. While many surveys of nutrition knowledge include fat-related questions, these often relate to disease links, not to understanding of the fat content of foods. In contrast to the public recognition of fats and disease, studies in the UK generally have shown that consumers are poor at categorizing selected foods as high $v$. low in fat (for example, see Anderson et al. 1988; Towler \& Shepherd, 1990). In a recent study comparing actual and judged fat content of foods (Mela, 1993), we found a consistent tendency to overestimate the fat content of foods low in fat and underestimate those high in fat. Estimates of fat content were characterized by wide deviations from true values, and were particularly poor for several specific foods.

A final point here is that consumers may hold views about high-fat diets which do not clearly correspond to their views of specific high-fat foods. For example, Tuorila \& Pangborn (1988) found that American females gave high ratings for liking specific high-fat foods, while reporting disliking 'high-fat foods' as a generic category. We (Lloyd et al. 1993) found that British consumers had more negative beliefs regarding the effects of specific dietary changes which might effect a reduction in fat intake than about reducing fat intake outright.

The results of these studies suggest that one major barrier to the adoption of reduced-fat diets may not be related to specific food-related obstacles, but to a belief that change has already been made or is not needed. We have found that provision of feedback relating to the fat content of different foods and food groups and their contribution to fat intake led to improvements in perceived ease of change. Taken together with other information, this suggests that identifying and targeting the origins of and ability to assess personal fat intakes would be a beneficial step in improving personal attitude toward and ability to modify dietary habits in a manner likely to improve long-term compliance. 


\section{CONCLUSIONS: BEHAVIOURAL MEASURES AS AN ADJUNCT TO NUTRITIONAL STUDIES}

The examples presented here, which are largely derived from literature of the behavioural sciences or represent multidisciplinary efforts of nutritionists and behavioural scientists, suggest that this collaboration has a great deal to offer in terms of ideas and methodologies which may be applied to understanding eating behaviour and its outcomes. These range from an understanding of the fundamental bases for food and nutrient selection, through assessment of personal preferences, to the larger social psychological factors which may contribute to explaining and potentially modifying consumer behaviour.

Unfortunately, while the field of nutrition readily recognizes and incorporates the contributions of physiologists, biochemists, and (even) epidemiologists, there remains a strange reluctance to extend this acceptance to behavioural scientists. Indeed, it has been the personal experience of this author (who originally trained in classical nutritional biochemistry) that those of us who conduct their research with behavioural scientists are viewed with scepticism, and are seen to be well outside the mainstream, if even recognized as nutritionists at all. There are still many situations in which investigators make extensive physiological and dietary intake measures, but fail to include even obvious psychosocial measures which might have significant explanatory power (e.g. Johnson et al. 1994).

Determinants of eating behaviour and food choice are increasingly accepted as suitable topics for fundamental research in nutrition. Furthermore, when longestablished dietary goals are not being met, it is appropriate to consider a shift in the balance of applied nutrition research from further refining these goals towards understanding and modifying consumer behaviour. In order to do this well, it is critical for nutritionists to ensure that they are using the best methodologies and expertise to address these issues.

\section{REFERENCES}

Aaron, J. I., Evans, R. E. \& Mela, D. J. (1995). Paradoxical effect of a nutrition labelling scheme in a student cafeteria. Nutrition Research (In the Press).

Aaron, J. I., Mela, D. J. \& Evans, R. E. (1994). The influences of attitudes, beliefs and label information on perceptions of reduced-fat spread. Appetite 22, 25-37.

Ackerman, S. H., Albert, M., Shindledecker, R. D., Gayle, C. \& Smith, G. P. (1992). Intake of different concentrations of sucrose and corn oil in preweanling rats. American Journal of Physiology 262, R624-R627.

Ackroff, K., Vigorito, M. \& Sclafani, A. (1990). Fat appetite in rats: The response of infant and adult rats to nutritive and non-nutritive oil emulsions. Appetite 15, 171-188.

Anderson, A. S., Umapathy, D., Palumbo, L. \& Pearson, D. W. M. (1988). Nutrition knowledge assessed by a structured questionnaire in a group of medical in-patients. Journal of Human Nutrition and Dietetics 1, 39-46.

Beauchamp, G. K. \& Engelman, K. (1991). High salt intake. Sensory and behavioral factors. Hypertension 17, Suppl. 1, 176-181.

Bertino, M., Beauchamp, G. K. \& Engelman, K. (1982). Long-term reduction in dietary sodium alters the taste of salt. American Journal of Clinical Nutrition 36, 1134-1144.

Bertino, M., Beauchamp, G. K. \& Engelman, K. (1986). Increasing dietary salt alters salt taste preference. Physiology and Behavior 38, 203-213.

Birch, L. L. (1992). Children's preferences for high-fat foods. Nutrition Reviews 50, 249-255.

Birch, L. L., McPhee, L., Steinberg, L. \& Sullivan, S. (1990). Conditioned flavor preferences in young children. Physiology and Behavior 47, 501-505. 
Blais, C. A., Pangborn, R. M., Borhani, N. O., Ferrell, M. F., Prineas, R. J. \& Laing, B. (1986). Effect of sodium restriction on taste responses to sodium chloride: A longitudinal study. American Journal of Clinical Nutrition 44, 232-243.

Bligh, M. E., DeStefano, M. B., Kramlik, S. K., Douglass, L. W., Dubuc, P. \& Castonguay, T. W. (1990). Adrenal modulation of the enhanced fat intake subsequent to fasting. Physiology and Behavior 48, 373-381.

Booth, D. A. (1985). Food-conditioned eating preferences and aversions with interoceptive elements: Conditioned appetites and satieties. Annals of the New York Academy of Sciences 443, $22-41$.

Booth, D. A., Mather, P. \& Fuller, J. (1982). Starch content of ordinary foods associatively conditions human appetite and satiation, indexed by intake and eating pleasantness of starch-paired foods. Appetite 3, $163-184$.

Cannon, G. (1992). Food and Health: The Experts Agree. London: Consumers' Association.

Drewnowski, A. (1992). Food preferences and the opioid system. Trends in Food Science and Technology 3, 97-99.

Drewnowski, A., Brunzell, J. D., Sande, K., Iverius, P. H. \& Greenwood, M. R. C. (1985). Sweet tooth reconsidered: Taste responsiveness in human obesity. Physiology and Behavior 35, 617-622.

Drewnowski, A. \& Greenwood, M. R. C. (1983). Cream and sugar: Human preferences for high-fat foods. Physiology and Behavior 30, 629-633.

Elizilde, G. \& Sclafani, A. (1990). Fat appetite in rats: Flavor preferences conditioned by nutritive and non-nutritive oil emulsions. Appetite 15, 189-197.

Galef, B. G. (1991). A contrarian view of the wisdom of the body as it relates to dietary self-selection. Psychological Review 98, 218-223.

Greene, G. W., Rossi, S. R. \& Reed, G. (1993). The effect of feedback on dietary intent to reduce fat. Topics in Clinical Nutrition 9, 20-28.

Johnson, R. K., Goran, M. I. \& Poehlmen, E. T. (1994). Correlates of underreporting of energy intake in healthy older men and women. American Journal of Clinical Nutrition 59, 1286-1290.

Johnson, S. L., McPhee, L. \& Birch, L. L. (1991). Conditioned preferences: Children prefer flavors associated with high dietary fat. Physiology and Behavior 50, 1245-1251.

Kanarak, R. B. \& Dushkin, H. (1988). Peripheral serotonin administration selectively reduces fat intake in rats. Pharmacology Biochemistry and Behavior 31, 113-122.

Kern, D. L., McPhee, L., Fisher, J., Johnson, S. \& Birch, L. L. (1993). The postingestive consequences of fat condition preferences for flavors associated with high dietary fat. Physiology and Behavior 54, 71-76.

Laitinen, J. H., Tuorila, H. M. \& Uusitupa, M. I. J. (1991). Changes in hedonic responses to sweet and fat in recently diagnosed non-insulin-dependent diabetic patients during diet therapy. European Journal of Clinical Nutrition 45, 393-400.

Leibowitz, S. F. \& Kim, T. (1992). Impact of a galanin antagonist on exogenous galanin and natural patterns of fat ingestion. Brain Research 599, 148-152.

Lloyd, H. M., Green, M. W. \& Rogers, P. J. (1994). Cognitive performance and mood effects of iso-caloric lunches differing in fat and carbohydrate content. Physiology and Behavior 56, 51-57.

Lloyd, H. M., Paisley, C. M. \& Mela, D. J. (1993). Changing to a low fat diet: Attitudes and beliefs of UK consumers. European Journal of Clinical Nutrition 47, 361-373.

Lloyd, H. M., Paisley, C. M. \& Mela, D. J. (1995). Barriers to the adoption of reduced fat diets in a UK population. Journal of the American Dietetic Association 95, 316-322.

Mattes, R. D. (1993). Fat preference and adherence to a reduced-fat diet. American Journal of Clinical Nutrition 57, 373-381.

Mela, D. J. (1990). The basis of dietary fat preferences. Trends in Food Science and Technology 1, 71-73.

Mela, D. J. (1992). The perception and acceptance of dietary fat: What, who, why? British Nutrition Foundation Nutrition Bulletin 17, Suppl. 1, 74-86.

Mela, D. J. (1993). Consumer estimates of the percent energy from fat in common foods. European Journal of Clinical Nutrition 47, 361-373.

Mela, D. J. \& Catt, S. L. (1995). Ontogeny of human taste and smell preferences and their implications for food selection. In Long Term Consequences of Early Environments [C. J. K. Henry and S. J. Ulijaszek, editors]. London: Cambridge University Press (In the Press).

Mela, D. J., Langley, K. \& Martin, A. (1994a). Sensory assessment of fat content: Effect of emulsion and subject characteristics. Appetite 22, 67-81.

Mela, D. J., Langley, K. R. \& Martin, A. (1994b). No effect of oral or sample temperature on sensory assessment of fat content. Physiology and Behavior 56, 655-658. 
Mela, D. J. \& Marshall, R. J. (1992). Sensory properties and perceptions of fats. In Dietary Fats: Determinants of Preference, Acceptance, and Consumption, pp. 43-57 [D. J. Mela, editor]. London: Elsevier Applied Science.

Mela, D. J. \& Sacchetti, D. S. (1991). Sensory preferences for fats in foods: relationships to diet and body composition. American Journal of Clinical Nutrition 53, 908-915.

Mela, D. J., Trunck, F. \& Aaron, J. I. (1993). No effect of extended home use on liking for sensory characteristics of reduced-fat foods. Appetite 21, 117-129.

Ministry of Agriculture, Fisheries and Food (1993). National Food Survey 1992. Annual Report on Household Food Consumption and Expenditure. London: HM Stationery Office.

Paisley, C. M. (1994). Barriers to the adoption and maintenance of reduced-fat diet. PhD Thesis, University of Reading.

Pangborn, R. M., Bos, K. E. O. \& Stern, J. S. (1985). Dietary fat intake and taste responses to fat in milk by under-, normal, and overweight women. Appetite 6, 25-40.

Pangborn, R. M. \& Giovanni, M. A. (1984). Dietary intake of sweet foods and of dairy fats and resultant gustatory responses to sugar in lemonade and to fat in milk. Appetite 5, 317-327.

Ramirez, I. (1992). Chemoreception for fat: Do rats sense triglycerides directly? Appetite 18, $193-206$.

Ray, J. W. \& Klesges, R. C. (1993). Influences on the eating behavior of children. Annals of the New York Academy of Sciences 699, 57-69.

Reed, D. R. \& Friedman, M. I. (1990). Diet composition alters the acceptance of fat by rats. Appetite 14, 219-230.

Reed, D. R., Mela, D. J. \& Friedman, M. I. (1992). Sensory and metabolic influences on fat intake. In Dietary Fats: Determinants of Preference, Acceptance, and Consumption, pp. 117-137 [D. J. Mela, editor]. London: Elsevier Applied Science.

Rogers, P. J. \& Lloyd, H. M. (1994). Nutrition and mental performance. Proceedings of the Nutrition Society $53,443-546$.

Rogers, P. J. \& Richardson, N. J. (1993). Why do we like drinks that contain caffeine? Trends in Food Science and Technology 4, 108-111.

Rozin, P. (1981). The study of human food selection and the problems of 'stage 1 science'. In Nutrition and Behavior, pp. 1-10 [S. A. Miller, editor]. Philadelphia: Franklin Institute Press.

Rozin, P. (1989). The role of learning in the acquisition of food preferences by humans. In Handbook of the Psychophysiology of Human Eating, pp. 205-227 [R. Shepherd, editor]. Chichester: Wiley.

Rozin, P. \& Fallon, A. E. (1981). The acquisition of likes and dislikes for foods. In Criteria of Food Acceptance: How Man Chooses What He Eats, pp. 35-48 [J. Solms and R. L. Hall, editors]. Zurich: Forster Verlag.

Rozin, P. N. \& Schulkin, J. (1990). Food selection. In Handbook of Behavioral Neurobiology, pp. 297-328 [E. M. Stricker, editor]. New York: Plenum.

Schaal, B. \& Orgeur, P. (1992). Olfaction in utero: Can the rodent model be generalized? Quarterly Journal of Experimental Psychology 44B, 245-278.

Schiffman, S. S., Graham, B. G., Vance, A. R., Gaillard, K., Warwick, Z. S. \& Erickson, R. P. (1992). Detection thresholds for emulsified oils in young and elderly subjects. Chemical Senses 17, 693 Abstr.

Sclafani, A. (1990). Nutritionally-based learned flavor preferences in rats. In Taste, Experience, and Feeding, pp. 139-156 [E. D. Capaldi and T. L. Powley, editors]. Washington, DC: American Psychological Association.

Sclafani, A. \& Ackroff, K. (1993). Deprivation alters rats' flavor preferences for carbohydrates and fats. Physiology and Behavior 53, 1091-1099.

Sheiham, A., Marmot, M., Taylor, B. \& Brown, A. (1990). Recipes for health. In British Social Attitudes, the 7th Report, pp. 145-165 [R. Jowell, S. Witherspoon, L. Brook and B. Taylor, editors]. Aldershot: Gower.

Shepherd, R. (1988). Belief structure in relation to low-fat milk consumption. Journal of Human Nutrition and Dietetics 1, 421-428.

Shepherd, R. (1989). Factors influencing food preferences and choice. Handbook of the Psychophysiology of Human Eating, pp. 1-24 [R. Shepherd, editor]. Chichester: Wiley.

Shepherd, R. (1992). Application of social psychological models to fat intake. In Dietary Fats: Determinants of Preference, Acceptance, and Consumption, pp. 9-26 [D. J. Mela, editor]. London: Elsevier Applied Science.

Shepherd, R. \& Farleigh, C. A. (1989). Sensory assessment of foods and the role of sensory attributes in determining food choice. In Handbook of the Psychophysiology of Human Eating, pp. 25-56. [R. Shepherd, editor]. Chichester: Wiley. 
Sörhede, M., Mei, J. \& Erlanson-Albertsson, C. (1993). Enterostatin: A gut-brain peptide regulating fat intake in rat. Journal of Physiology 87, 273-275.

Sparks, P., Shepherd, R., Wieringa, N. \& Zimmermanns, N. (1995). Perceived behavioural control, unrealistic optimism and dietary change: An exploratory study. Appetite (In the Press).

Stafleu, A., de Graaf, C. \& van Staveren, W. A. (1991-2). A review of selected studies assessing social-psychological determinants of fat and cholesterol intake. Food Quality and Preference 3, 183-200.

Stafleu, A., de Graaf, C., van Staveren, W. A. \& de Jong, M. A. (1994). Attitudes towards high-fat foods and their low-fat alternatives: Reliability and relationship with fat intake. Appetite 22, 183-196.

Tate, J. \& Cade, J. (1990). Public knowledge of dietary fat and coronary heart disease. Health Education Journal 49, 32-35.

Tepper, B. J. \& Friedman, M. I. (1989). Diabetes and high-fat/low-carbohydrate diet enhance the acceptability of oil emulsions to rats. Physiology and Behavior 45, 717-721.

Towler, G. \& Shepherd, R. (1990). Development of a nutritional knowledge questionnaire. Journal of Human Nutrition and Dietetics 3, 255-264.

Tuorila, H. (1987). Selection of milks with varying fat contents and related overall liking, attitudes, norms and intentions. Appetite 8, 1-14.

Tuorila, H. (1992). Preferences and attitudes related to fat-containing foods. In Dietary Fats: Determinants of Preference, Acceptance, and Consumption, pp. 27-42 [D. J. Mela, editor]. London: Elsevier Applied Science.

Tuorila, H. \& Pangborn, R. M. (1988). Prediction of reported consumption of selected fat-containing foods. Appetite 11, 81-95.

Warwick, Z. S., Shiffman, S. S. \& Anderson, J. B. (1990). Relationship of dietary fat content to food preferences in young rats. Physiology and Behavior 48, 581-586.

Weatherford, S. C., Greenberg, D., Gibbs, J. \& Smith, G. P. (1990). The potency of D-1 and D-2 receptor antagonists is inversely related to the reward value of sham-fed corn oil and sucrose in rats. Pharmacology Biochemistry and Behavior 37, 317-323.

Weinstein, N. D. (1989). Optimistic biases about personal risks. Science 246, 1232-1233.

Welch, C. C., Grace, M. K., Billington, C. J. \& Levine, A. S. (1993). NPY induces fat selection in fat-preferring rats. FASEB Journal 7, A88 Abstr. 